\title{
Derivation of Strike and Dip in Sedimentary Terrain Using 3D Image Interpretation Based on Airborne LiDAR Data
}

\author{
Chih-Hsiang Yeh ${ }^{1,2}$, Yu-Chang Chan ${ }^{2, *}$, Kuo-Jen Chang ${ }^{3}$, Ming-Lang Lin ${ }^{1}$, and Yu-Chung Hsieh ${ }^{4}$ \\ ${ }^{1}$ Department of Civil Engineering, National Taiwan University, Taipei, Taiwan \\ ${ }^{2}$ Institute of Earth Sciences, Academia Sinica, Taipei, Taiwan \\ ${ }^{3}$ Department of Civil Engineering, National Taipei University of Technology, Taipei, Taiwan \\ ${ }^{4}$ Central Geological Survey, Ministry of Economic Affairs, Taipei, Taiwan
}

Received 29 November 2013, revised 1 July 2014, accepted 2 July 2014

\begin{abstract}
Traditional geological mapping may be hindered by rough terrain and dense vegetation resulting in obscured geological details. The advent of airborne Light Detection and Ranging (LiDAR) provides a very precise three-dimensional (3D) digital terrain model (DTM). However, its full potential in complementing traditional geological mapping remains to be explored using 3D rendering techniques. This study uses two types of 3D images which differ in imaging principles to further explore the finer details of sedimentary terrain. Our purposes are to demonstrate detailed geological mapping with 3D rendering techniques, to generate LiDAR-derived 3D strata boundaries that are advantageous in generating 2D geological maps and cross sections, and to develop a new practice in deriving the strike and dip of bedding with LiDAR data using an example from the north bank of the Keelung River in northern Taiwan. We propose a geological mapping practice that improves efficiency and meets a high-precision mapping standard with up to $2 \mathrm{~m}$ resolution using airborne LiDAR data. Through field verification and assessment, LiDAR data manipulation with relevant 3D visualization is shown to be an effective approach in improving the details of existing geological maps, specifically in sedimentary terrain.
\end{abstract}

Key words: Mapping of sedimentary terrain, LiDAR-derived strike and dip of bedding, Airborne LiDAR application, 3D image interpretation

Citation: Yeh, C. H., Y.C.Chan, K. J. Chang, M.L.Lin, and Y.C. Hsieh, 2014: Derivation of strike and dip in sedimentary terrain using 3D image interpretation based on airborne LiDAR data. Terr. Atmos. Ocean. Sci., 25, 775-790, doi: 10.3319/TAO.2014.07.02.01(TT)

\section{INTRODUCTION}

Two of the main tasks in geological mapping focus on defining strata boundaries and collecting the strike and dip of bedding, which greatly influence the reliability of stratigraphic unit reconstruction for geological maps. Traditionally, geological mapping is implemented using field investigations which may be hindered by dense vegetation and terrain that are difficult to access. For practical reasons the scale of geological mapping is usually set at the $1: 100000$ to 1:25000-scale in local areas (e.g., CGS 2002, 2005; Lisle et al.2011), resulting in geological detail simplification. Thus, improving the reliability of geological maps has always been an important objective for finer scale applications.

In recent decades remote sensing data such as aerial

\footnotetext{
* Corresponding author

E-mail:yuchang@earth.sinica.edu.tw
}

photographs and satellite images have been used for geological mapping (Crósta and Moore 1989; Drury 1993; Dueholm et al. 1993; Dong and Leblon 2004; Bedini 2009; Rogge et al. 2009; Roy et al. 2009; Van der Meer et al. 2012; Lato et al. 2013). However, in areas with dense vegetation, such photo-geological mapping cannot easily detect subtle geological lineaments or elements on the ground. The advent of airborne Light Detection and Ranging (LiDAR), offers a solution to overcome the vegetation cover problem and enhance topographical data spatial resolution, reaching $4 \mathrm{~m}$ or less (Kraus and Pfeifer 1998; Haugerud et al. 2003). Such high-resolution topographic data greatly increases geological applications such as landslide mapping (Chang et al. 2005; Chen et al. 2006; Glenn et al. 2006; Arrowsmith and Zielke 2009; de Rose and Basher 2011; Ventura et al. 2011; Bremer and Sass 2012), fault and lineament mapping (Chan et al. 2007; Chang et al. 2010; Lan et al. 2010; Sutinen et al. 2014), 
and lithological mapping (Webster et al. 2006; Grebby et al. 2010). Although these studies have successfully recognized geological lineaments and morphology, the potential for applying airborne LiDAR data for the mapping of geological features, such as sedimentary strata boundaries, remains to be explored. For example, the traditional 2D top-view LiDARderived images cannot effectively display side views of the terrain, making it difficult to confidently trace strata boundaries using visual interpretation. Furthermore, the unevenly distributed and limited quantity of bedding strike and dip obtained using traditional field measurements often make detailed mapping very difficult or even impossible.

The main goal of this study is to produce a geological map with ample and reliable strike and dip estimates using airborne LiDAR data to complement fieldwork. A LiDARderived digital terrain model (DTM), having $2 \mathrm{~m}$ resolution or better, is recommended for use because it helps in locating the strata boundaries, particularly in areas with dense vegetation. Other types of DTMs, such as those derived from aerial, satellite or InSAR images, are not used as we would specifically emphasize the applicability of LiDARderived DTM in this study for complementing fieldwork. Visual interpretation of the geological features is kept as the main image-interpreting approach, which is familiar to most experienced geologists. We adopted three-dimensional (3D) visualization techniques to improve the readability of the LiDAR images in mapping 19 Miocene rock strata boundaries at the north bank of the Keelung River in northern Taiwan. From the strata boundary mapping results we further developed new approaches to derive two types of strike and dip: (1) the direct LiDAR-derived strike and dip and (2) the interpolation-derived strike and dip. The former is used for improving the existing geological maps and the latter is used for predicting the strike and dip values at a certain location and shallow depths.

\section{GEOLOGICAL BACKGROUND}

The study area of about 46 square kilometers $(9.1 \times 5.1 \mathrm{~km}$ rectangular area in Fig. 1) is located on the north bank of the Keelung River in northern Taiwan. This area has long been recognized as a part of the fold-and-thrust belt produced by the collision of the Eurasian tectonic plate and the Philippine Sea plate (Seno 1977; Suppe 1980; Teng 1990). The stratigraphy is composed mainly of Miocene formations and folded into the Badu syncline. According to relevant studies (Teng et al. 2001; CGS 2005), these Miocene formations can be divided into four units from old to young: the Mushan formation (Ms Fm.), Taliao formation (Tl Fm.), Shihti formation (St Fm.), and Nankang formation (Nk Fm.). In general, the main lithologies can be categorized into three types of rocks: sandstone, shale, and sandstoneshale alternation. The area shows large-scale cuesta topography leaning towards the southeast with dip angles of about
10 - 30 degrees, covered with heavy vegetation over $90 \%$ of the ground (Fig. 2). Such topographic conditions cause complex and poorly accessible terrain that increases the difficulties of traditional field and photo-geological mapping. So far the published large-scale geological maps are in the scale of 1:50000 and 1:25000 in the study area (CGS 2002, 2005). A comparison of strata boundary distributions between these two existing geological maps within a restricted square demonstration area is shown in Fig. 3.

With dip-slope topography and sandstone-shale stratigraphy this study area is recognized as a geologically sensitive area for human use and prone to landslide hazards (Wang et al. 2013). However, due to its location between two densely populated cities, Taipei and Keelung, this area has been subjected to human development, including transport infrastructures and large communities, resulting in a higher frequency dip-slope landslide occurrence. A number of cases even caused heavy casualties. In the continuing development situation, understanding detailed distribution of different rock types and bedding attitudes is a critical task necessary to assist disaster prevention. Finer geological mapping will play an important role and provide indispensable information for mitigating geological disasters.

\section{METHODS}

This study adopted 3D visualization technologies to improve the geological mapping using LiDAR-derived DTM. Apart from re-mapping originally mapped lineaments with better precision, these 3D imaging methods are able to map unexplored strata boundaries in detail and subsequently derive the bedding strike and dip.

\subsection{LiDAR Data Acquisition}

Airborne LiDAR is a remote sensing tool offering high-resolution topographic data, which can virtually remove vegetation on the ground for topographic and geological observations. The LiDAR data for the north bank of the Keelung River were obtained in April 2006 by the Central Geological Survey of Taiwan. A single-channel airborne scanner, Optech ALTM 30/70 model with $200 \mathrm{kHz}$ sampling capability was used for the LiDAR survey. The scanner was mounted on a helicopter with a flight speed of $219 \mathrm{~km} \mathrm{~h}^{-1}$. The flight altitude was about $1800 \mathrm{~m}$ above sea level and the ground-helicopter distance ranged between $1000-1500 \mathrm{~m}$. Other LiDAR survey technical specifications were as follows: the operating pulse repetition rate was $71 \mathrm{kHz}$; the field of view (FOV) was \pm 20 degrees; the scan rate was $38 \mathrm{~Hz}$. Three flight lines covered the entire study area with each swath width about $730 \mathrm{~m}$. The overlap between adjacent swaths was about $40 \%$, or approximately $290 \mathrm{~m}$. The vertical misfit among swaths ranged from $-13-6 \mathrm{~cm}$, with a standard deviation of about $17 \mathrm{~cm}$. 


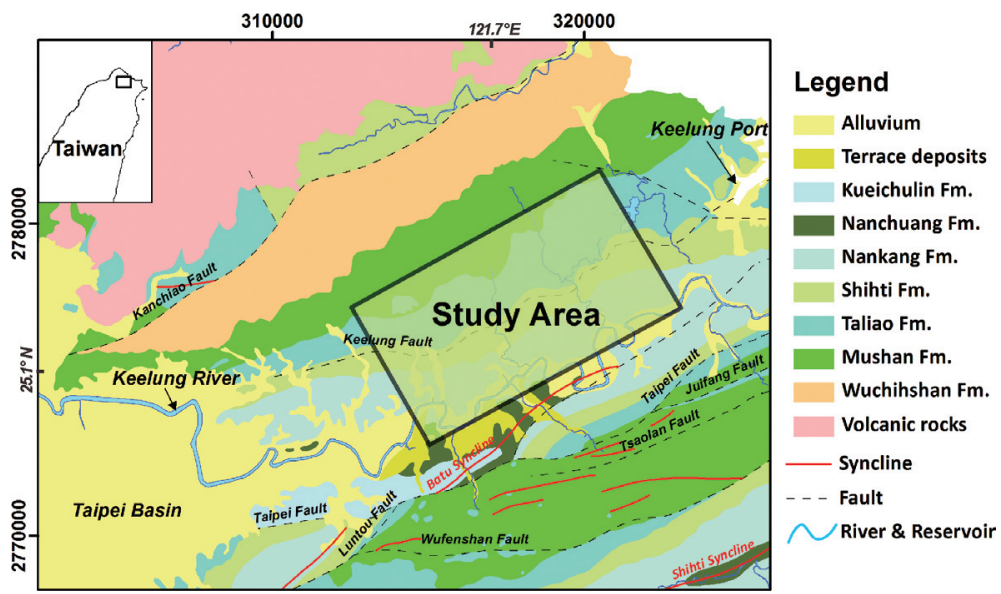

Fig. 1. Geological map of the northern Taipei area adapted from the regional geological map created by the Central Geological Survey of Taiwan (CGS 2005). The study area is indicated by the black box that is located on the north bank of the Keelung River. The study area used for demonstrating geological mapping is about $46 \mathrm{~km}^{2}$.

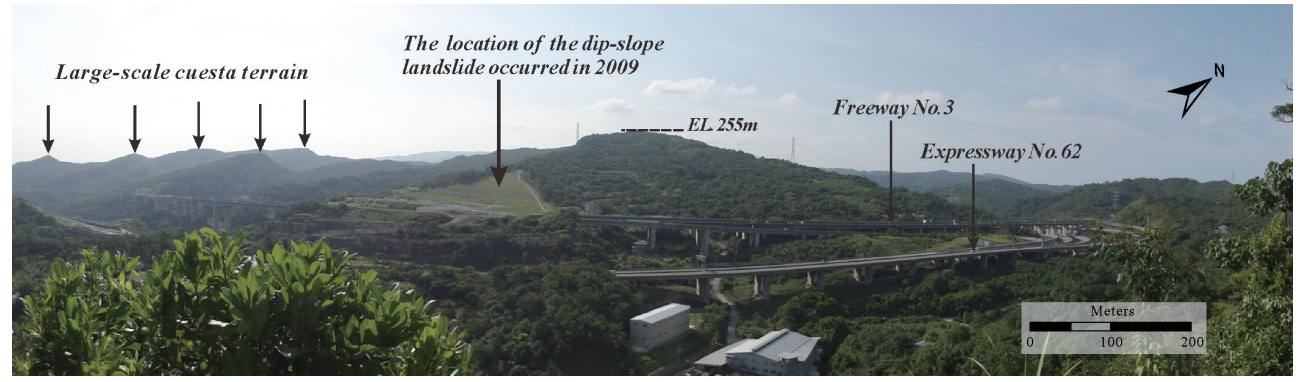

Fig. 2. Field photograph showing cuesta and dense vegetation topography. The center-left location near the freeway is the dip-slope site of a landside that occurred in 2009 (TGS 2011). The construction of two major highways resulted in several unstable slope sites that are landslide high-risk areas.
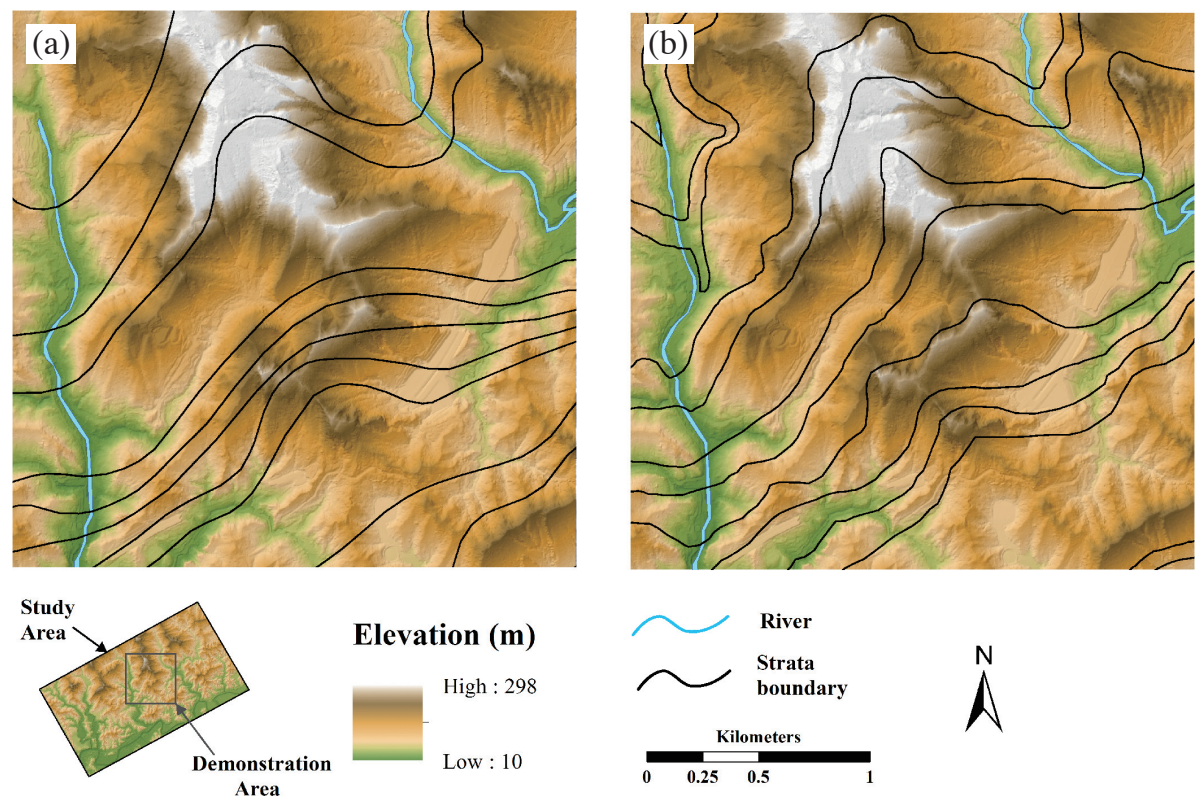

Fig. 3. Strata boundaries extracted from existing geological maps in a $2.5 \times 2.5 \mathrm{~km}$ demonstration area within Fig. 1. (a) 1:50000 and (b) 1:25000-scale maps from the Taipei geological map and Badu lithological map provided by the Central Geological Survey of Taiwan. The base map is the $2 \mathrm{~m}$ color-coded shaded-relief LiDAR image. 
The classified point clouds acquired from the LiDAR returns after removing objects in the air including clouds and birds were recorded in the LAS format of 3D coordinates in the WGS84 2-degree Transverse Mercator projection system (TM2). The survey collected approximately 130000000 data points within the study area. The average density of the original point clouds is about 2.8 points $\mathrm{m}^{2}$. After removing nonground points the average effective density decreased to about 0.8 points $\mathrm{m}^{2}$, which is still sufficient to generate a DTM with a grid size of $2 \mathrm{~m}$. Comparing kinematic GPS measurements the vertical error may vary according to the different terrain types, such as bare ground and forest. The average mean errors for the LiDAR data used in this study, the RMS and STD are $0.037,0.168$, and $0.165 \mathrm{~m}$, respectively.

\subsection{LiDAR 3D Images}

Traditionally, the LiDAR data are first processed using shading or hypsometric tinting to obtain 2D images for assisting visual geological interpretation. Although such an imaging method allows an understanding of the topographic relief in $2 \mathrm{D}$ images, its poor ability to provide visual positioning in 3D space limits high-resolution geological applications, such as mapping sedimentary formations at a scale larger than 1:5000. In this study two types of 3D imaging techniques were used: 3D flythrough and anaglyph to best extract the LiDAR data potential for detailed geological mapping.

\subsubsection{LiDAR 3D Flythrough}

Three dimensional flythrough is a common method to exhibit a 3D terrain draping aerial photographs and satellite imagery. It is a virtual 3D image (also called $2.5 \mathrm{D}$ image) and usually carried out using 3D navigation software such as Google Earth (http://earth.google.com) or ArcScene (http://www.arcgis.com). However, image distortion in the slope and vegetation regions interferes with the geological interpretation. We adopted high-resolution LiDAR topography data to clearly display the surface geological details. Unclear or masked geological lineaments including sedimentary boundaries can be easily positioned and traced. The LiDAR image viewing angle can be set arbitrarily according to the required terrain perspectives as shown in Fig. 4. Obviously, the LiDAR image with 3D flythrough can present good image effects for visual geological interpretation.

Sedimentary bedding, which is the interface between two different lithological beds, is the image interpretation objective. The interface can be shown as a characteristic line because of differential erosion effects. During geological mapping implementation using LiDAR 3D flythrough, we can arbitrarily change the viewing directions to better examine the terrain. At the same time image processing including shading, elevation exaggeration, etc. are carried out to enhance the topographic and geological characteristic lines for the best observations. Continuous lineaments can therefore be identified and traced with high confidence in $3 \mathrm{D}$ space, and also be mapped on a $2 \mathrm{D}$ plane using projection. Because each bedding trace is composed of a series of $3 \mathrm{D}$ coordinate points we can clearly express the strata boundaries in the 3D pattern. To transfer the 3D points into a $2 \mathrm{D}$ geological map the $3 \mathrm{D}$ points are first converted into the same geological map coordinate system. The 2D points are projected directly onto the geological map plane by removing the vertical component. A schematic diagram of bedding plane lineament mapping using $3 \mathrm{D}$ flythrough is shown in Fig. 5.

\subsubsection{LiDAR Anaglyph Image}

Topographic and geological applications using stereoscopic images can be traced back to the middle of the $19^{\text {th }}$ century (Kuenen 1950). Interpreters used a desktop stereoscope and a pair of raw aerial photographs for surface observations. Today stereoscopic images can be digitally produced for rapid and convenient uses in many different 3D technologies, such as anaglyph, shutter, polarizing, glass less type, etc. (Wickens and Hollands 1999; Lee et al. 2000; Howard 2002; Kooi and Toet 2004; Bowman et al. 2004). Among them, the anaglyph was adopted for our 3D geological mapping because of its economy and efficiency. A LiDAR anaglyph image of the study area is shown in Fig. 6. Note that it is necessary to wear a pair of special glasses: typically red-cyan or red-blue glasses, for revealing an integrated stereoscopic image. From the image we can experience vivid stereovision for identifying topographic relief.

The LiDAR anaglyph image is used in this study for solving situations that cannot be interpreted by the LiDAR 3D flythrough images, especially in rough terrain such as a valley. Figure 7a is a LiDAR 3D flythrough image showing a valley terrain within the study area. Although we can see surface lineaments of various types on the LiDAR 3D flythrough image, they are less vivid in 3D than those shown by a LiDAR anaglyph. Thus, we produced a pair of corresponding left- and right-eye images and built a LiDAR anaglyph image (Fig. 7b) with a favorable viewing direction. From this image we can identify lineament types, such as bedding interfaces or gullies, and match them across the valley.

\subsection{Deriving the Values of Strike and Dip of Bedding}

Strike and dip are basic information that provides quantitative bedding attitudes. Strike and dip measurements are obtained through field strategies that are best suited to the outcrop condition (Twiss and Moores 2007). However, the number of strike and dip measurements is usually restricted in poorly accessible areas, resulting in undesirable data gaps. LiDAR data application significantly improves the geological mapping, but the strike and dip resolution in 
maps is still not significantly improved. We suggest an efficient and reliable method to calculate strike and dip values that complements the fieldwork to solve this problem and obtain finer geological mapping.

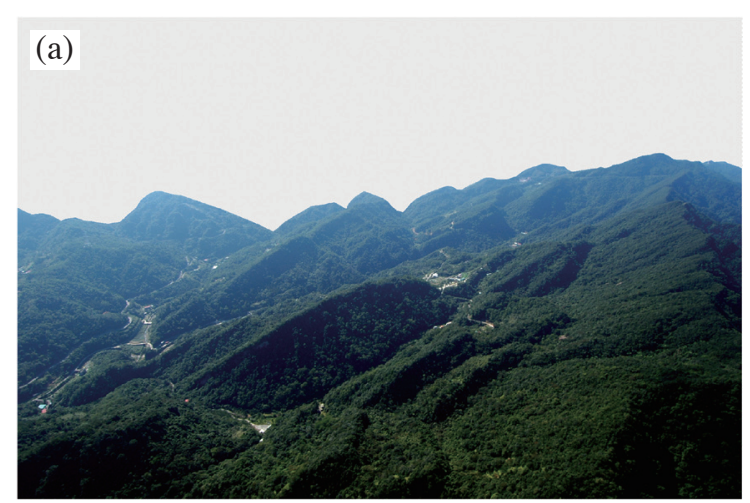

\subsubsection{Deriving Bedding Strike and Dip from LiDAR Data}

The traditional method of obtaining strike and dip is to

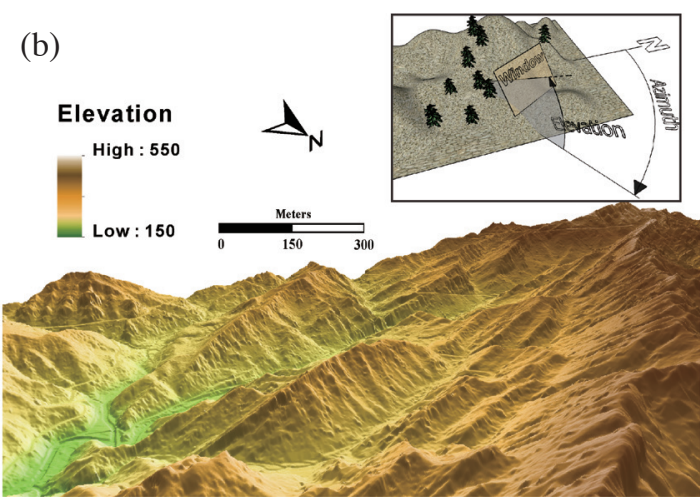

Fig. 4. Comparison of the surface perspective view from air photo and LiDAR 3D flythrough. (a) A perspective photograph taken from a helicopter showing a regional topography of sedimentary terrain with heavy vegetation. (b) A LiDAR 3D flythrough with an adjusted view angle similar to that of (a). The schematic diagram shows the elements of the 3D flythrough observations. Notice the clear appearance of strata boundaries in the simulated 3D flythrough where the vegetation has been virtually removed.
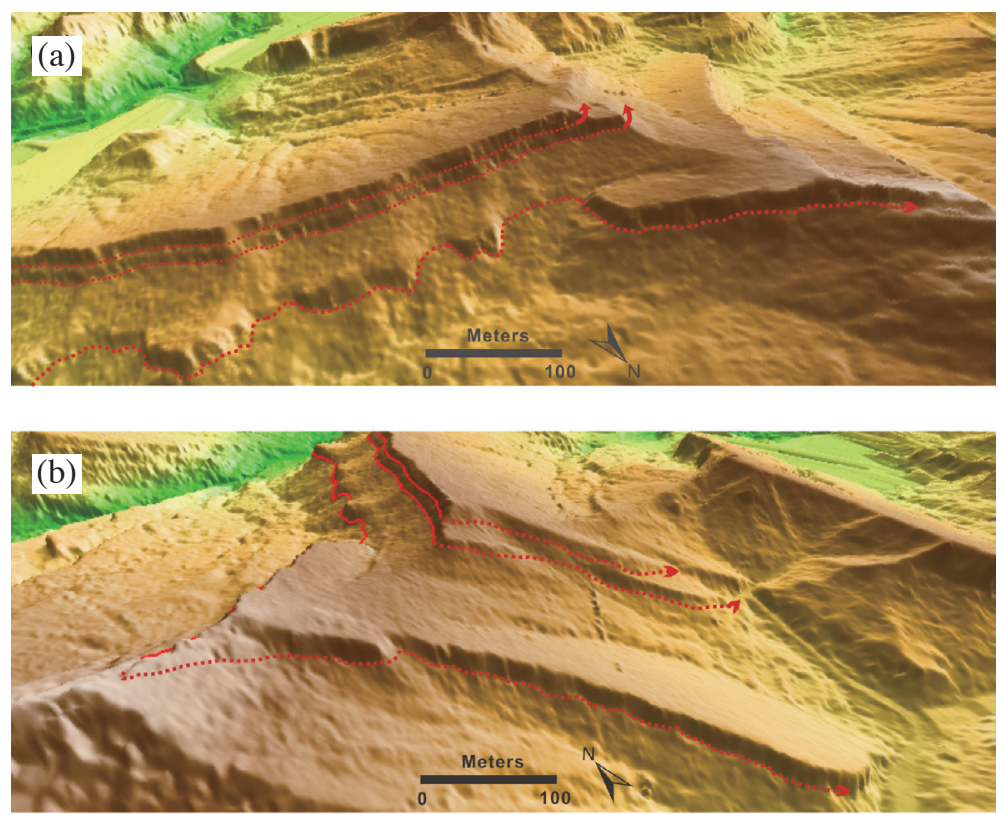

(c)

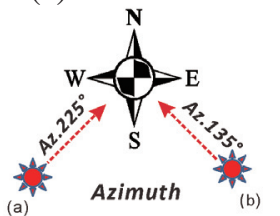

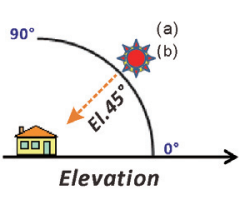

Elevation

Shading Angle

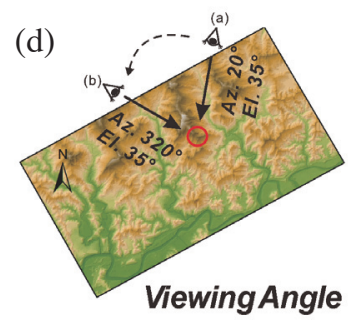

Fig. 5. Two examples of sedimentary bedding visual interpretation. (a) The viewing window with an azimuth of $20^{\circ}$ as the viewing direction. The dashed lines and arrows indicate the sedimentary bedding and their continuing directions. (b) The viewing window with an azimuth of $320^{\circ}$ as the viewing direction. (c) Schematic diagram of shading directions in the above two images. The upper image is shaded by $255^{\circ}$ azimuth and $45^{\circ}$ elevation; the lower image is shaded by $135^{\circ}$ azimuth and $45^{\circ}$ elevation. (d) Schematic diagram showing the observation location and the viewing directions. 


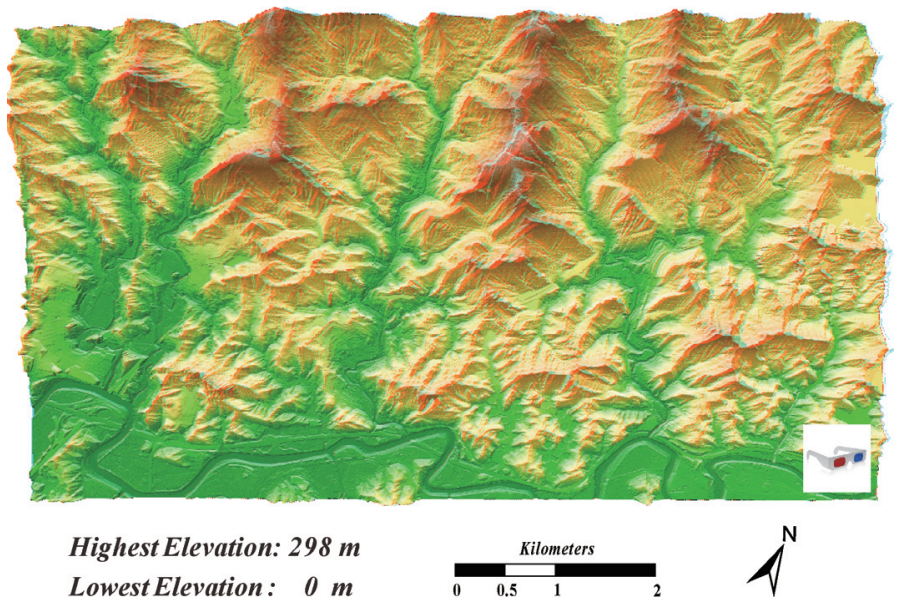

Fig. 6. Demonstration of the LiDAR-derived 3D anaglyph over the study area. A pair of anaglyph viewing glasses is required to perceive the vivid 3D geological mapping effects.
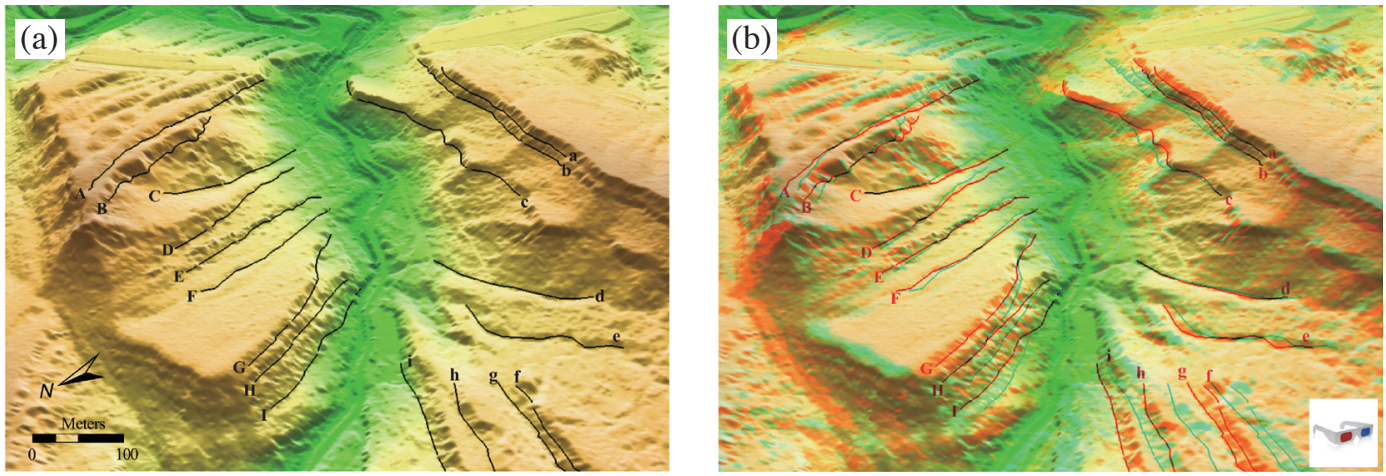

Fig. 7. Two examples of visual interpretation of sedimentary bedding with matching strata across a valley using the 3D anaglyph images. (a) The 3D flythrough image showing the geological linear features on both sides of a valley. The lineaments are marked in uppercase and lowercase characters on the left and right sides of the valley, respectively. (b) The 3D anaglyph image showing the geological linear features on both sides of a valley. The linear features including the sedimentary boundaries and erosional gullies can be interpreted from the 3D anaglyph image. We can easily identify and match sedimentary boundaries, such as $\mathrm{A}-\mathrm{c}, \mathrm{G}-\mathrm{g}, \mathrm{H}-\mathrm{h}$, and $\mathrm{I}-\mathrm{i}$, and the gullies as $\mathrm{C}, \mathrm{d}$, and $\mathrm{e}$.

measure both the direction and the inclined angle between a bedding plane and the horizontal plane at field outcrops. Obtaining LiDAR-derived bedding strike and dip follows the same principle, but it defines a sedimentary bedding plane using the LiDAR data. Three measurement points over a sedimentary bedding plane define a measurement triangle exactly, but, in practice, more than three points are needed for better results. These measurement points are used to compute a regression plane for obtaining a measurement triangle. The regression plane can be represented by:

$z=a x+b y+c$

where $x$ and $y$ are the longitude and latitude in the TM2 coordinate system, $z$ is the elevation above a given datum, and $a, b$, and $c$ are estimated coefficients. Next we acquire the normal measurement triangle vector and take the cross product with the normal horizontal plane vector to derive the strike and dip of the measurement triangle. The strike-anddip derivation process is schematically shown in Fig. 8. For clarity, the symbol for the LiDAR-derived strike and dip is different from that of the outcrop strike and dip. For the LiDAR-derived strike and dip the dip direction is represented by an arrowhead and the symbol is labeled at the centroid of the measurement triangle. From the regression computation the LiDAR-derived strike and dip data obviously have better fits than those from the traditional field method that only apply to a small outcrop surface. Thus, better quality data for strike and dip can be obtained for more detailed description of the stratigraphy under investigation.

\subsubsection{Interpolated Smoothing Bedding Surface}

Interpolated smoothing bedding surfaces are obtained from a 3D bedding attitude model based on LiDAR data. 
The model construction is based on the bedding regression surfaces and their linear interpolation. The zigzag curves of the bedding traces extending in 3D space can be fitted using corresponding regression surfaces (see Fig. 9). The regression surface is defined as a first degree polynomial in the two-variable equation:

$z=c_{1}+c_{2} x+c_{3} y+c_{4} x y$ where $c_{1}, c_{2}, c_{3}$, and $c_{4}$ are the estimated coefficients for the regression surface. Consequently, the strike and dip of each point on the regression surface can be derived from a spatial vector calculation. Using the regression-surface equation, the dip direction can be found at any point on the surface by calculating the gradient of a two-variable function:

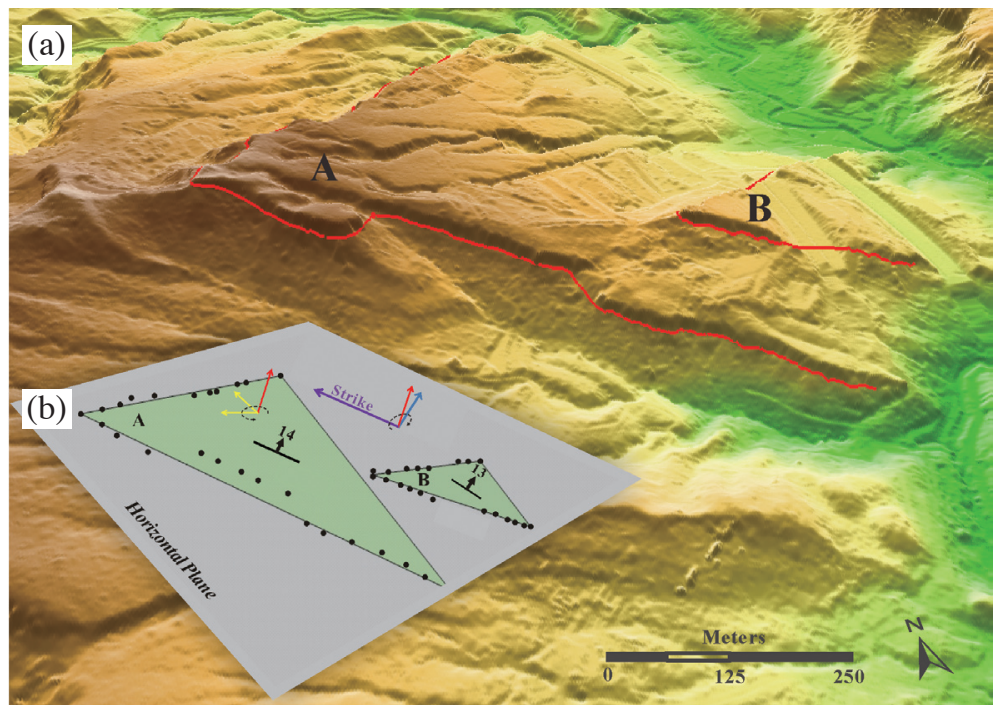

Fig. 8. How the LiDAR-derived strike and dip are calculated in the laboratory. (a) The two bedding planes A and B for demonstrating calculation of the LiDAR-derived strike and dip. (b) Schematic diagram of the spatial vector calculation for bedding planes A and B. The two triangles are the average planes regressed from the dots that indicate well-defined points on the interpreted sedimentary boundaries. The two yellow arrows are the vectors on plane A, and the red arrow is the normal vector of plane A. We take the cross product of the blue vector (a unit vector of dip) with the red vector to derive the strike vector (the purple vector) and the dip of plane A. A similar procedure is applied to plane B. The derived strike and dip of the planes $\mathrm{A}$ and $\mathrm{B}$ are $\left(\mathrm{N} 33^{\circ} \mathrm{E}, 14^{\circ}\right)$ and $\left(\mathrm{N} 19^{\circ} \mathrm{E}, 13^{\circ}\right)$, respectively. The strike and dip symbols are marked at the centroid of the two triangles.

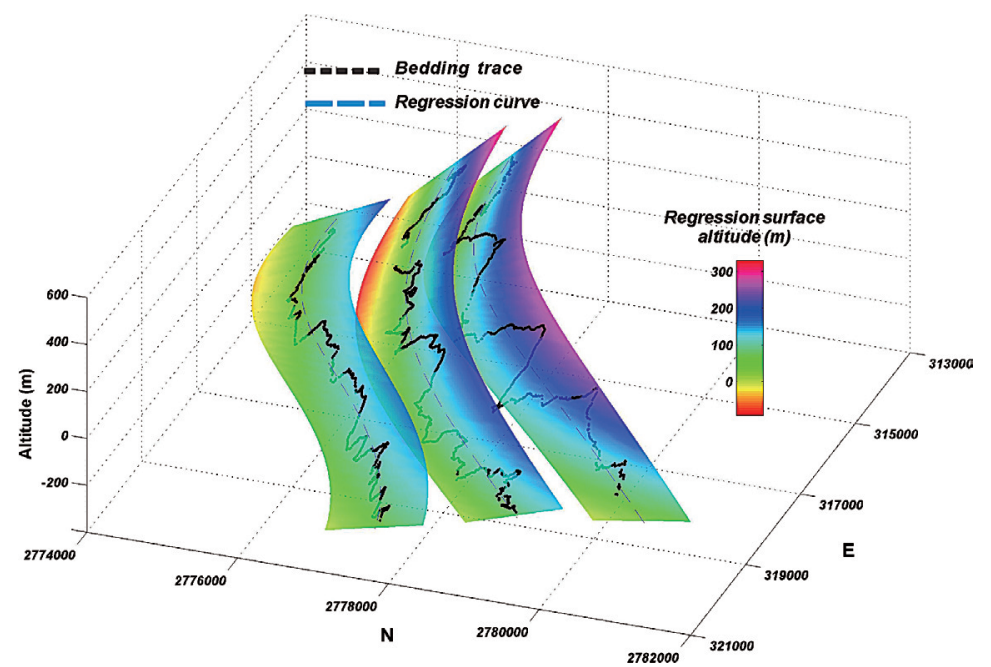

Fig. 9. Three regression surfaces within the study area shown in 3D perspective view. The solid zigzag lines indicate the sedimentary bedding traces, and the dashed lines indicate the regression lines. Three numerical equations can be usefully constructed to represent the sedimentary surfaces of T4, S0, and N4 (See Fig. 11 for definition of symbols) as shown below: $z=-528.43+0.025 x+0.158 y-1.465 \times 10^{-5} x y(\mathrm{~T} 4)$; $z=-939.35+0.071 x+0.290 y-3.052 \times 10^{-5} x y(\mathrm{~S} 0) ; z=-747.63+0.017 x+0.292 y-2.256 \times 10^{-5} x y(\mathrm{~N} 4)$; where $z$ denotes elevation, and $x$ and $y$ are the longitude and latitude in the TM2 coordinate system. Before the calculation, $x$ and $y$ were shifted -313000 and $-2773000 \mathrm{~m}$, respectively. 
where $\vec{v}_{d i p}$ is the dip direction and $\vec{i}$ and $\vec{j}$ are the unit vectors of the $x$ and $y$ directions. We can then calculate the dip slope from the following equation:

$S_{d i p}=\left\|\vec{u}_{d i p}\right\|=\left\|\vec{v}_{d i p} /\right\| \vec{v}_{d i p}\|\|$

where $S_{d i p}$ is the dip slope, $\vec{u}_{d i p}$ is the dip unit vector and the notation \|\| indicates the vector length. The dip value in degrees can be calculated easily from the dip slope. The strike vector can be calculated at any point over the regression surface using the following equation:

$\vec{v}_{\text {strike }}=\vec{n}_{\text {dip }} \times \vec{n}_{\text {surface }}$

where $\vec{v}_{\text {strike }}$ is the strike direction, $\vec{n}_{\text {dip }}$ is the dip unit vector and $\vec{n}_{\text {zsurface }}$ is the unit normal vector of the regression surface of $z$. The strike value can be calculated from the angle between north and the strike direction. In general a firstdegree polynomial with a two variable equation is used to derive the interpolation-derived strike surface and bedding dip. The surface can be determined with four constant coefficients and regular vector analysis will help determine the strike and dip through the previously stated equations.

After acquiring all of the regression surfaces and the strikes and dips on those surfaces, we use an algorithm for linear interpolation to build a 3D model of the bedding attitudes. Because the regression surfaces appear below the dip-slope surfaces, the surface morphology will not interfere with the recognition of a typical dip slope. The main purpose of the interpolated smoothing bedding surface is for predicting the subsurface strike and dip pattern at shallow depth. The interpolation-derived strike and dip, if well constrained by field or LiDAR-derived strike and dip measurements, can be useful for mining, underground or tunnel engineering projects during site investigation and evalu- ation stages. For example, the subsurface strike and dip prediction will help us evaluate and select a corresponding construction method in advance for optimally solving engineering geological problems.

\section{MAPPING RESULTS}

\subsection{Sedimentary Bedding Traces}

All sedimentary bedding traces in this study were identified using visual image interpretation. We used existing geological maps to assist in identifying the general sedimentary strata distribution. The interpreted bedding traces should meet basic bedding characteristics, such as overall continuity and parallelism. Other lineaments that do not match the two characteristics, such as gullies and traces of human development, would be removed during visual interpretation processes. Some interpreted bedding traces pass through the entire study area from NE - SW and they are classified as well-defined bedding traces. In contrast, those that do not show continuous traces are classified as not so well-defined or even poorly-defined bedding traces, depending on the completeness of the mapped bedding traces. Accordingly, we were able to identify 19 well-defined bedding traces to show the sedimentary strata distribution pattern. The bedding trace 3D mapping results are shown in Fig. 10. Based on the stratigraphic units in existing geological maps, the 19 bedding traces are numbered sequentially based on their corresponding positions in the previously published stratigraphic units (see Fig. 11): T0 - 6: Taliao Fm; S0 - 2: Shiti Fm; N0 - 8: Nankang Fm.

\subsection{LiDAR-Derived Strike and Dip of Bedding}

The LiDAR-derived bedding plane strike and dip are deduced from each measurement triangle (see section 3.3.1). Triangle selection in the study area is based on the following restrictions for better measurement results:

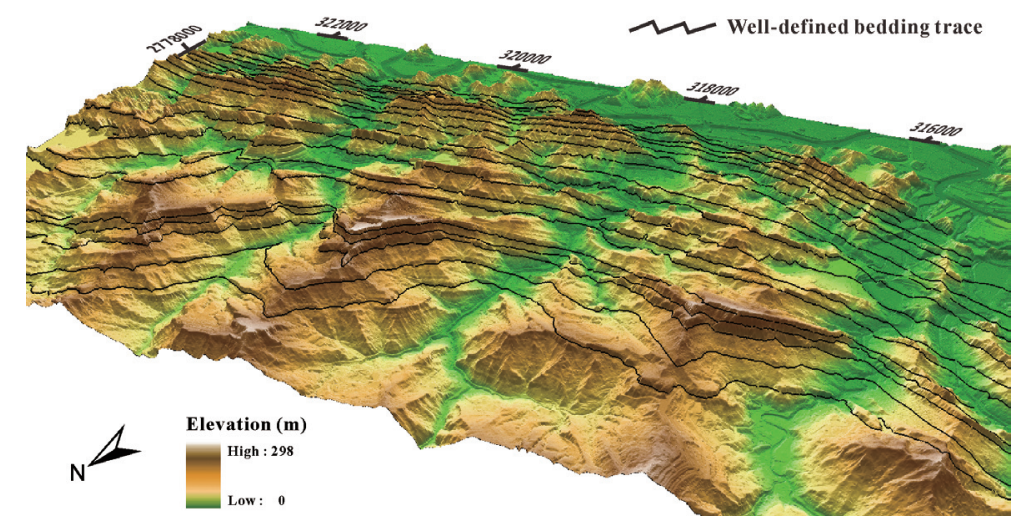

Fig. 10. The mapping results of the sedimentary bedding traces (in black solid lines) presented in 3D perspective view with the TM2 coordinate system. A total of 19 major sedimentary beddings, mostly well-defined bedding, are interpreted in the study area. The figure is shown with a shading angle of $315^{\circ}$ and two times elevation exaggeration. The viewing window is set at the viewing angle of $20^{\circ}$ in azimuth and $45^{\circ}$ in elevation. 


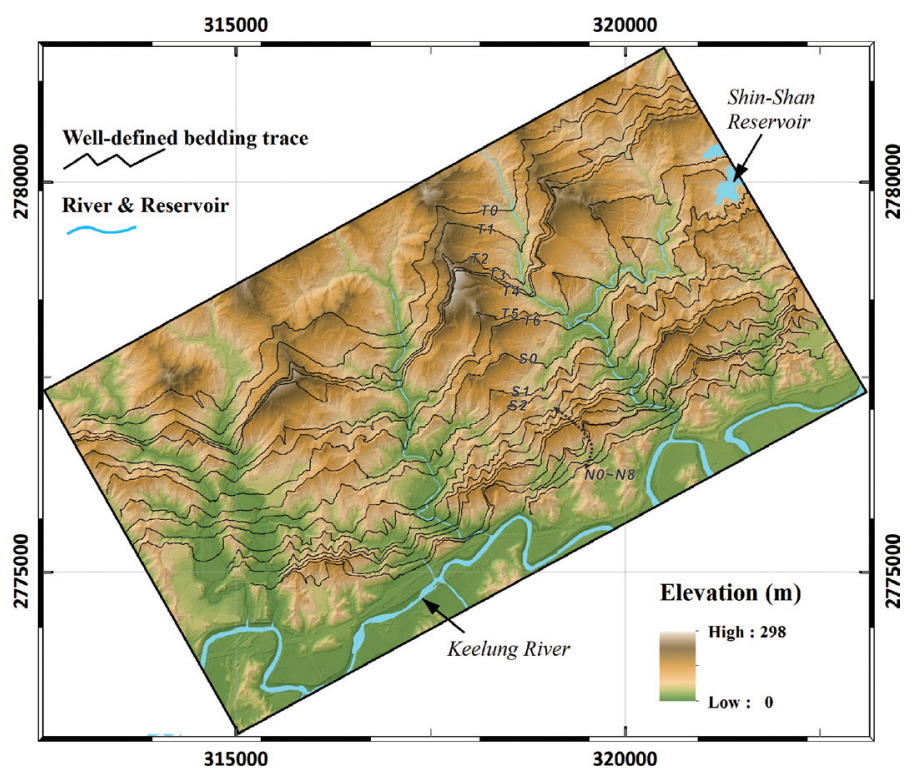

Fig. 11. The mapping results of the sedimentary bedding traces (in solid lines) shown in a 2D map. From north to south, these strata boundaries are named as T0 - 6, S0 - 2, and N0 - 8. The first letter indicates that the bedding is related to the Tl, St, and Nk Formations, respectively. The T0, S0, and N0 are the newly improved boundaries of the stratigraphic formations in northern Taiwan.

(1) The shape is approximately an isosceles triangle and each interior angle is in the $30-120^{\circ}$ range. This restriction will ensure that the measurement triangle is not too elongated in shape and will desirably reduce the sensitivity of the observed coordinate point values for the final calculated strike and dip values.

(2) The measurement triangle should have a representative size of about $10000 \pm 2000$ square meters. In general, the size of the measurement triangle should not be too large because the strata are curved in nature. It should also not be too small because it will undesirably increase the sensitivity of the observed coordinate point values for the final calculated strike and dip values.

(3) The $R^{2}$ of the regression calculation should be greater than 0.85 . The threshold of the $\mathrm{R}^{2}$ value for selecting the measurement triangles is usually arbitrarily determined. We selected triangles with the $\mathrm{R}^{2}$ value greater than 0.85 for goodness of fit as well as to have enough measurement triangles for the study area.

We determined 39 measurement triangles that complied with the above restrictions to calculate the LiDAR-derived strike and dip. For regression analysis the goodness of fit of the LiDAR-derived strike and dip is shown in Table 1. The table includes the standard error of the estimate (SEE) and coefficient of determination $\left(\mathrm{R}^{2}\right)$. The SEE indicates the dispersion degree of regression model prediction, and the $\mathrm{R}^{2}$ indicates the goodness of fit of the regression plane. The strike and dip mapping results including the outcrop and LiDAR-derived measurements are shown in Fig. 12a. There are only 17 field outcrops recording the strike and dip within the study area and their density is 0.37 points $\mathrm{km}^{-2}$. After adding the new 39 LiDAR-derived measurements, the strike and dip density increased significantly to 1.22 points $\mathrm{km}^{-2}$ with better measurement distribution. In addition, we also produced a detailed geological profile with the new mapping results with enhanced stratigraphic column reliability (Fig. 12b).

\subsection{Interpolation-Derived Strike and Dip of Bedding}

The method of obtaining interpolation-derived strike and dip is preliminarily described in section 3.3.2. In the demonstration area, $2.5 \times 2.5 \mathrm{~km}$, near the center of our study area (see Fig. 3), we included 14 well-defined beddings from LiDAR images which go through the area for generating 14 regression surfaces. The goodness of fit analysis for the 14 regression surfaces is shown in Table 2 . A 3D bedding attitude model was built through a series of spatial vector calculations [Eqs. (3) - (5)] and linear interpolation. The model's elevation data region ranges from the ground surface to about $200 \mathrm{~m}$ below sea level. The greatest advantage of this method is its ability to predict the strike and dip distribution underground at shallow depths. To illustrate this advantage we selected the sea-level plane and the ground surface for demonstration. The results from the demonstration area show that the strike values increased towards the SW at both sea level and on the ground surface (Figs. 13a, b), and that the dip values are larger on the SE side at both sea level and on the ground surface (Figs. 13c, d). The interpolation-derived strike and dip prediction is very helpful for engineering designs such as tunnels, foundations and slope stability. 
Yeh et al.

Table 1. Detailed properties of LiDAR-derived strike and dip.

\begin{tabular}{|c|c|c|c|c|c|c|}
\hline \multicolumn{2}{|c|}{ Location of TM2 } & \multirow{2}{*}{ Area of measurement triangle $\left(\mathbf{m}^{2}\right)$} & \multirow{2}{*}{ Strike } & \multirow{2}{*}{ Dip } & \multirow{2}{*}{ SEE (m) } & \multirow{2}{*}{$\mathbf{R}^{2}$} \\
\hline $\mathbf{E}$ & $\mathbf{N}$ & & & & & \\
\hline 320294 & 2780927 & 10845 & $\mathrm{~N} 78^{\circ} \mathrm{E}$ & $18^{\circ} \mathrm{S}$ & 9.3 & 0.92 \\
\hline 320802 & 2780053 & 8933 & $\mathrm{~N} 59^{\circ} \mathrm{E}$ & $12^{\circ} \mathrm{S}$ & 8.5 & 0.90 \\
\hline 320967 & 2779307 & 9686 & $\mathrm{~N} 43^{\circ} \mathrm{E}$ & $14^{\circ} \mathrm{E}$ & 7.2 & 0.91 \\
\hline 321579 & 2778444 & 10787 & $\mathrm{~N} 69^{\circ} \mathrm{E}$ & $27^{\circ} \mathrm{S}$ & 6.9 & 0.95 \\
\hline 318718 & 2780499 & 11314 & $\mathrm{~N} 36^{\circ} \mathrm{E}$ & $20^{\circ} \mathrm{E}$ & 8.7 & 0.93 \\
\hline 318957 & 2780010 & 10545 & $\mathrm{~N} 34^{\circ} \mathrm{E}$ & $17^{\circ} \mathrm{E}$ & 8.2 & 0.91 \\
\hline 319687 & 2779653 & 11550 & $\mathrm{~N} 31^{\circ} \mathrm{E}$ & $14^{\circ} \mathrm{E}$ & 9.8 & 0.89 \\
\hline 320057 & 2779244 & 11559 & $\mathrm{~N} 15^{\circ} \mathrm{E}$ & $13^{\circ} \mathrm{E}$ & 7.8 & 0.90 \\
\hline 320558 & 2778451 & 11855 & $\mathrm{~N} 46^{\circ} \mathrm{E}$ & $20^{\circ} \mathrm{S}$ & 8.9 & 0.94 \\
\hline 321269 & 2777891 & 11166 & $\mathrm{~N} 67^{\circ} \mathrm{E}$ & $20^{\circ} \mathrm{S}$ & 6.7 & 0.96 \\
\hline 321508 & 2777498 & 11423 & $\mathrm{~N} 62^{\circ} \mathrm{E}$ & $22^{\circ} \mathrm{S}$ & 4.8 & 0.92 \\
\hline 319186 & 2778742 & 10868 & $\mathrm{~N} 53^{\circ} \mathrm{E}$ & $11^{\circ} \mathrm{S}$ & 6.9 & 0.93 \\
\hline 320388 & 2777398 & 10184 & $\mathrm{~N} 58^{\circ} \mathrm{E}$ & $12^{\circ} \mathrm{S}$ & 9.5 & 0.92 \\
\hline 318852 & 2778787 & 10853 & $\mathrm{~N} 53^{\circ} \mathrm{E}$ & $12^{\circ} \mathrm{S}$ & 6.2 & 0.95 \\
\hline 319509 & 2777795 & 12012 & $\mathrm{~N} 52^{\circ} \mathrm{E}$ & $16^{\circ} \mathrm{S}$ & 8.8 & 0.89 \\
\hline 317669 & 2779596 & 11017 & $\mathrm{~N} 40^{\circ} \mathrm{E}$ & $16^{\circ} \mathrm{E}$ & 3.5 & 0.98 \\
\hline 317763 & 2779407 & 9497 & $\mathrm{~N} 37^{\circ} \mathrm{E}$ & $23^{\circ} \mathrm{E}$ & 5.5 & 0.94 \\
\hline 318039 & 2778981 & 11203 & $\mathrm{~N} 33^{\circ} \mathrm{E}$ & $25^{\circ} \mathrm{E}$ & 6.9 & 0.97 \\
\hline 317869 & 2778799 & 11727 & $\mathrm{~N} 33^{\circ} \mathrm{E}$ & $13^{\circ} \mathrm{E}$ & 4.1 & 0.94 \\
\hline 318206 & 2778199 & 12040 & $\mathrm{~N} 50^{\circ} \mathrm{E}$ & $21^{\circ} \mathrm{S}$ & 4.0 & 0.92 \\
\hline 318394 & 2778081 & 11414 & $\mathrm{~N} 54^{\circ} \mathrm{E}$ & $21^{\circ} \mathrm{S}$ & 3.9 & 0.94 \\
\hline 318274 & 2777602 & 8229 & $\mathrm{~N} 52^{\circ} \mathrm{E}$ & $23^{\circ} \mathrm{S}$ & 4.8 & 0.93 \\
\hline 318320 & 2777249 & 9164 & $\mathrm{~N} 63^{\circ} \mathrm{E}$ & $22^{\circ} \mathrm{S}$ & 4.4 & 0.92 \\
\hline 318583 & 2777051 & 10513 & $\mathrm{~N} 59^{\circ} \mathrm{E}$ & $28^{\circ} \mathrm{S}$ & 6.6 & 0.90 \\
\hline 318775 & 2776833 & 11271 & $\mathrm{~N} 63^{\circ} \mathrm{E}$ & $23^{\circ} \mathrm{S}$ & 9.2 & 0.89 \\
\hline 319061 & 2776414 & 10477 & $\mathrm{~N} 61^{\circ} \mathrm{E}$ & $26^{\circ} \mathrm{S}$ & 10.1 & 0.88 \\
\hline 317676 & 2777842 & 10633 & $\mathrm{~N} 59^{\circ} \mathrm{E}$ & $21^{\circ} \mathrm{S}$ & 8.5 & 0.91 \\
\hline 316601 & 2777147 & 13162 & $\mathrm{~N} 59^{\circ} \mathrm{E}$ & $13^{\circ} \mathrm{S}$ & 9.6 & 0.90 \\
\hline 317117 & 2775694 & 12017 & $\mathrm{~N} 75^{\circ} \mathrm{E}$ & $16^{\circ} \mathrm{S}$ & 6.9 & 0.91 \\
\hline 315634 & 2777789 & 12046 & $\mathrm{~N} 60^{\circ} \mathrm{E}$ & $11^{\circ} \mathrm{S}$ & 4.7 & 0.97 \\
\hline 315751 & 2777581 & 10587 & $\mathrm{~N} 66^{\circ} \mathrm{E}$ & $15^{\circ} \mathrm{S}$ & 7.1 & 0.90 \\
\hline 315865 & 2776679 & 9224 & $\mathrm{~N} 64^{\circ} \mathrm{E}$ & $25^{\circ} \mathrm{S}$ & 7.3 & 0.90 \\
\hline 316073 & 2776514 & 12074 & $\mathrm{~N} 71^{\circ} \mathrm{E}$ & $26^{\circ} \mathrm{S}$ & 8.4 & 0.89 \\
\hline 316128 & 2775854 & 11651 & $\mathrm{~N} 77^{\circ} \mathrm{E}$ & $18^{\circ} \mathrm{S}$ & 11.6 & 0.87 \\
\hline 316097 & 2775596 & 11905 & $\mathrm{~N} 84^{\circ} \mathrm{E}$ & $24^{\circ} \mathrm{S}$ & 6.5 & 0.90 \\
\hline 316265 & 2774999 & 11388 & $\mathrm{~N} 89^{\circ} \mathrm{E}$ & $23^{\circ} \mathrm{S}$ & 6.9 & 0.92 \\
\hline 314677 & 2776412 & 11614 & $\mathrm{~N} 89^{\circ} \mathrm{E}$ & $28^{\circ} \mathrm{S}$ & 3.5 & 0.96 \\
\hline 314225 & 2776851 & 8988 & $\mathrm{~N} 88^{\circ} \mathrm{E}$ & $26^{\circ} \mathrm{S}$ & 3.8 & 0.98 \\
\hline 313449 & 2776157 & 8654 & $\mathrm{~N} 89^{\circ} \mathrm{E}$ & $23^{\circ} \mathrm{S}$ & 4.7 & 0.95 \\
\hline Ave. & & 10874 & & & 6.9 & 0.92 \\
\hline
\end{tabular}

Note: SEE means standard error of the estimate. 

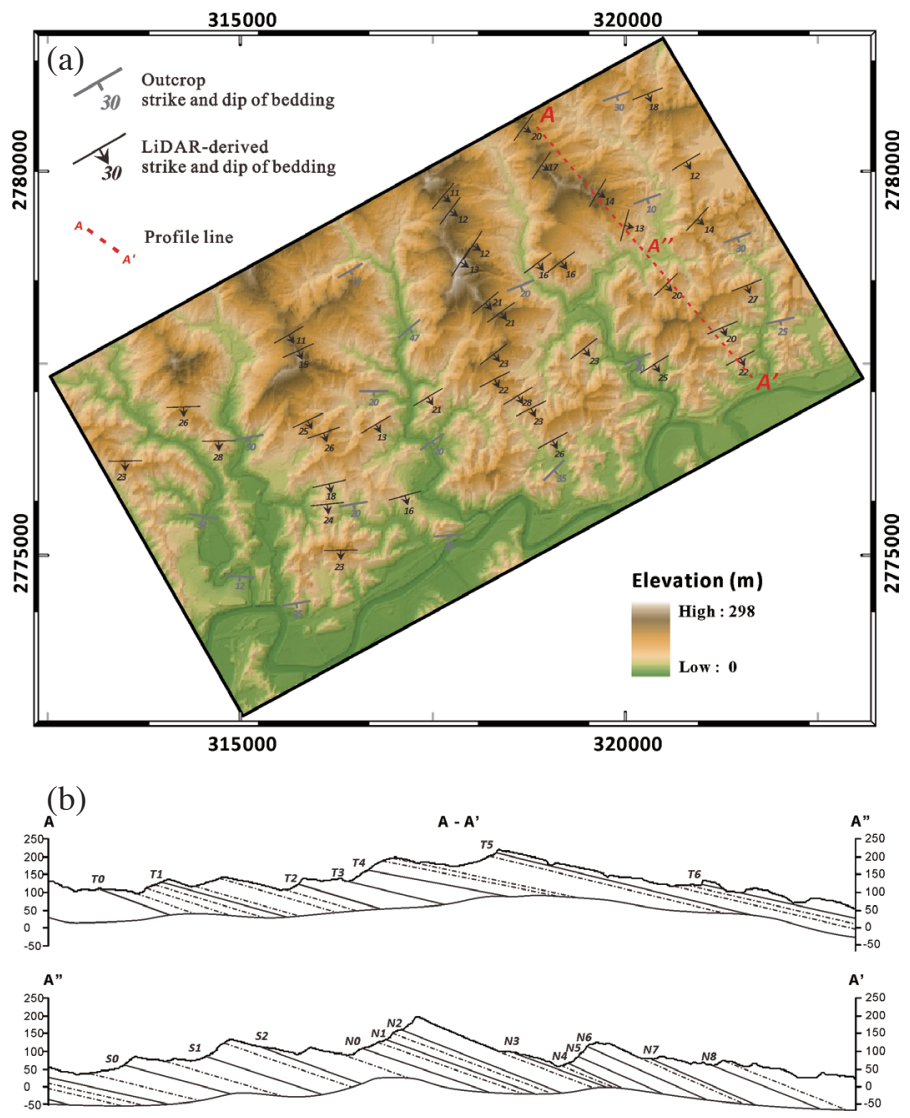

Fig. 12. Detailed mapping results of strike and dip and an example of a geological profile. (a) The LiDAR-derived (39 sites) and the outcrop (17 sites) strike and dip in the study area. (b) The geological profile A - A' showing detailed strata thickness, dip value and the location of the strata boundaries. The tilted solid lines indicate the boundaries of well-defined bedding traces. The tilted dashed lines indicate the boundaries of not so well-defined or poorly-defined bedding traces. Vertical exaggeration is twice the horizontal scale. The position of the A - A' profile line is shown in (a). Seven measurements of the LiDAR-derived strike and dip are distributed along this profile and represent the bedding dip of T0, 2, 5, 6, S1, N6, and 8, respectively. Other bedding dips are interpolated linearly.

Table 2. Goodness of fit of regression within the demonstration area $(2.5 \times 2.5 \mathrm{~km})$.

\begin{tabular}{ccrc}
\hline Name of strata boundary & Number of observation points & SEE (m) & $\mathbf{R}^{2}$ \\
\hline T0 & 383 & 14.09 & 0.92 \\
T1 & 279 & 15.59 & 0.93 \\
T2 & 282 & 15.60 & 0.94 \\
T3 & 345 & 17.1 & 0.93 \\
T4 & 251 & 14.92 & 0.96 \\
T5 & 413 & 7.62 & 0.98 \\
T6 & 447 & 6.61 & 0.99 \\
S0 & 427 & 8.97 & 0.97 \\
S1 & 449 & 11.74 & 0.87 \\
S2 & 383 & 8.91 & 0.89 \\
N0 & 385 & 10.75 & 0.86 \\
N1 & 412 & 11.46 & 0.85 \\
N2 & 414 & 8.38 & 0.94 \\
N3 & 479 & 7.46 & 0.96 \\
Ave. & 382 & 11.37 & 0.93 \\
\hline
\end{tabular}

Note: SEE means standard error of the estimate. 
(a)

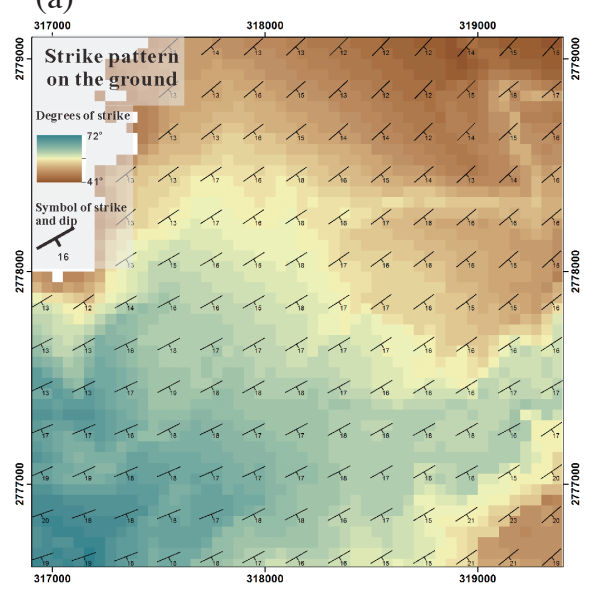

(c)

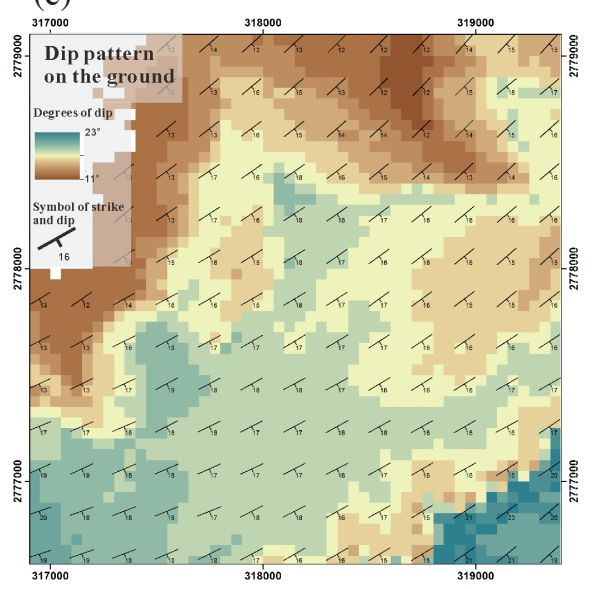

(b)

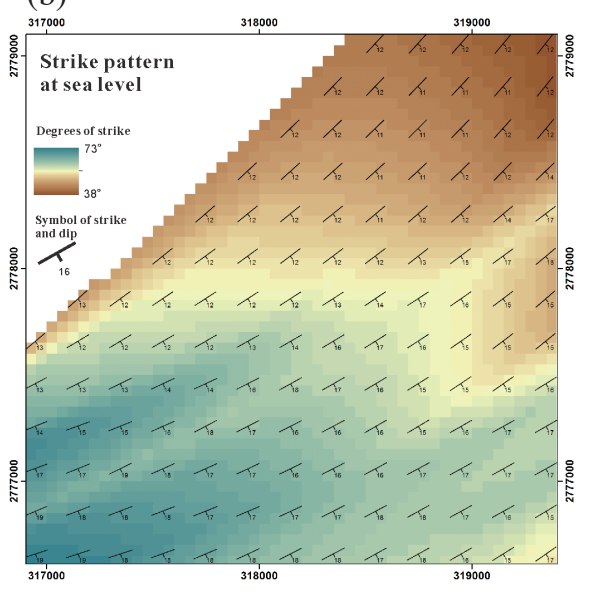

(d)

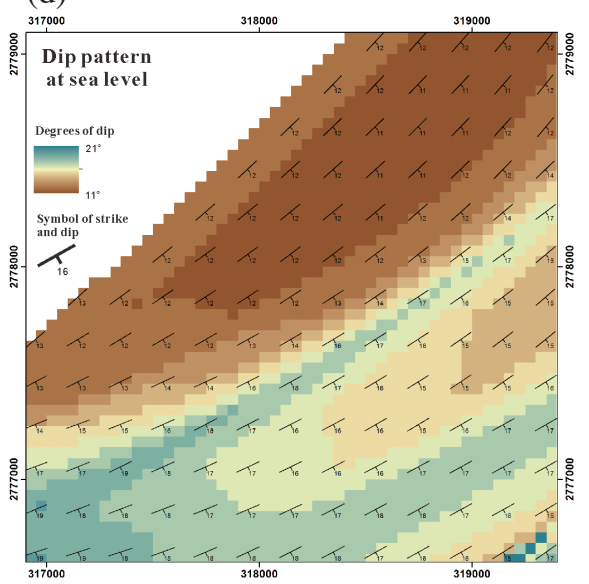

Fig. 13. Interpolation-derived bedding strike and dip. (a) Strike pattern on the ground surface. (b) Strike pattern at sea level. (c) Dip pattern on the ground surface. (d) Dip pattern at sea level in a selected demonstration area (see the dashed box within Fig. 2). The color ramp represents the degrees of strike or dip with a pixel size of $10 \times 10 \mathrm{~m}$. The symbols for strike and dip are labeled every $100 \times 100 \mathrm{~m}$. As revealed by the enhanced color pattern, the variation of the degrees of strike can be easily recognized.

\subsection{LiDAR-Based Strata Boundary Map}

The 3D imaging techniques helped us observe detailed strata boundaries. Through the strike and dip methods derived from LiDAR and image processing more reliable bedding attitudes can be obtained than using traditional field methods. Thus, based on the previous geological maps we can derive a LiDAR-based strata boundary map with finer scales (see Fig. 14). In the demonstration area we also added 16 beddings, in addition to the 14 well-defined beddings. The 16 new beddings can be identified explicitly, but often lack continuity. The number of strike and dip measurements in the demonstration area increased from 2 - 13, enhancing the geological description of the region. The existing geological maps (see Fig. 3) can be improved and complemented using the proposed LiDAR-based geological mapping. The final results of the improved geological maps show much more detailed geological features and should be very helpful for engineering applications.

\section{DISCUSSION}

\subsection{Geological Mapping in 3D vs. 2D}

In general, geological mapping using remote sensing images has large-scale, rapid and economic features (Drury 1993; Rogge et al. 2009). However, due to the limitations of 2D images, geological mapping still depends considerably on the geological information obtained in field investigations (Carranza and Hale 2002). Three dimensional imaging technologies retain all the advantages of remote sensing images and also provide more precise geological information. The overall differences between 3D and 2D geological mapping are described as follows:

(1) Differences in image readability. The $2 \mathrm{D}$ remote sensing image is restricted to an observed scene with a single viewing angle. Without long-term geological training, inexperienced observers find difficulty in grasping important geological information when viewing these images. Three dimensional image displays, however, provide 
interactive and straightforward stereo images so that observers with less geological experience are able to interpret the topographic and geological information correctly and efficiently.

(2) Differences in geological information acquisition. Although we can draw geological lineaments on 2D images, it is not straightforward to obtain the strata thickness and the strike and dip without field investigations. Three dimensional images help identify geological lineaments precisely and continuously in 3D space. The thickness and orientation of the strata can be easily obtained from direct visual observation or spatial geometry analysis. The results can then be used to quantify the underground geology of local areas that are important for city planning.

\subsection{Strike and Dip of Bedding}

Previously, clinometer measurements at field outcrops were the only method for acquiring bedding strike and dip (e.g., Twiss and Moores 2007). This study proposes a 3D space geometric analysis method to obtain the strike and dip precisely and rapidly. The proposed method imposes a triangle plane onto a sedimentary boundary and then applies a planar geometric algorithm for computing the strike and dip values. The advantages of this geometric analysis include:

(1) Obtaining the bedding strike and dip complementing field investigation when it is difficult. When appropriate triangle measurement planes are defined, we can obtain a great number of strike and dip estimates and no longer be restricted by the lack of field outcrops.

(2) Obtaining representative values of the regional trend of the strike and dip. The traditional method measures a point at a field outcrop with a clinometer. This method causes higher variability among different measurement points. Our proposed geometric analysis in 3D space method computes the strike and dip values by defining a relatively large measurement triangle plane. The values derived from such measurements represent the average within the selected triangle plane and should be more representative of the true bedding strike and dip at regional scale.

\subsection{Traditional and 3D LiDAR-Based Bedding Trace Maps}

Due to improvements in computer technology, traditional geological maps can be processed using digital procedures (Whitmeyer et al. 2010; de Donatis et al. 2012). Because of the need to measure geological elements, such as bedding plane and formation boundary in the field, the procedures use only indirect digitization methods, which convert field data from such geological elements into digital formats. In contrast, the definition of geological elements and the 3D LiDAR-based geological maps are efficiently derived from high-resolution DTMs. The differences between the two bedding trace mapping approaches include:

(1) Differences in density and coverage. The traditional approach depends on manual measurements and the distribution of outcrops. Detailed geological mapping is usually difficult to achieve at a scale of 1:5000 or greater when local geological field investigation is hindered by dense forest or terrain that are poorly accessible. The LiDAR DTM used for producing the 3D LiDAR-based bedding trace maps in this study has a horizontal resolution of $2 \mathrm{~m}$ and a vertical resolution of about $20 \mathrm{~cm}$. Its mapping scale can easily be applied at 1:2000.

(2) The ability to quantify geological information in 3D. Because the number of outcrops being surveyed is usually inadequate, bedding geometry and stratigraphic boundary are often mapped at very coarse scales, resulting in traditional geological maps having limited engineering applications. The 3D LiDAR-based bedding trace maps provide precise $3 \mathrm{D}$ positioning of the strata location, orientation and thickness that can be readily quantified to facilitate advanced numerical modeling for geological and engineering problems.

\subsection{Sources Affecting Mapping Quality}

Except for systematic errors such as GPS positioning and laser distance measuring, the visual image interpretation process is the main factor affecting strata boundary mapping quality. Generally, the sources affecting mapping quality may be attributed to the following situations.

(1) Low density of LiDAR ground points. This situation usually occurs in regions of dense vegetation and very steep slopes. The DTM resolution may be lower than the average, resulting in coarse geological features not favorable for identification (Fig. 15).

(2) Debris deposition covering bedding traces. Debris deposition from small or local landslides often covers some segments of bedding planes, particularly in the strata of alternating sandstone and shale layers (Fig. 15).

(3) River terraces and human constructions. These two situations make a large part of strata boundaries obscure. To minimize their influence, we can apply aerial photographs and satellite images to assist in 3D image interpretations and work on critical outcrops in the field for constraints (Fig. 15).

\subsection{Limitations of LiDAR 3D Strata Mapping}

In highly vegetated terrains, LiDAR 3D imaging is one of the best solutions for mapping geological and topographical features. These images were used mainly for bedding plane and stratigraphic boundary interpretation in this study. Nevertheless, such application is restricted in use under the following relatively complex geological conditions: 
(1) Sedimentary terrain with little differential erosion. Because the display of strata boundaries in sedimentary terrain on LiDAR images is highly dependent upon the effects of differential erosion, the boundary between two similar lithological beds can be difficult to interpret without clear differential erosion (see Fig.15).

(2) Complexly fractured sedimentary terrain. Complexly deformed rocks that contain a great number of joints and fractures may lead to irregular surface patterns from accelerated surface erosion. The irregular morphology may cause difficulties at recognizing bedding traces.

(3) Complexly folded and faulted sedimentary terrain. Severe folding and faulting may cause distorted and displaced bedding that is hard to identify and trace. Such complex terrain may need more works, such as strati- graphic correlation and fundamental structure determination, before further using image interpretation.

(4) Volcanic and metamorphic terrain. The pattern of sedimentary bedding is easily recognized on the LiDARderived images, but volcanic and metamorphic terrains show complex patterns that are hard to interpret and may need further studies.

\section{CONCLUSIONS}

Geological mapping with LiDAR-derived 3D images can be very effective for mapping regular sedimentary strata on a finer map scale, which should better meet the higher resolution requirements of engineering planning. In this study we remapped the bedding trace including its

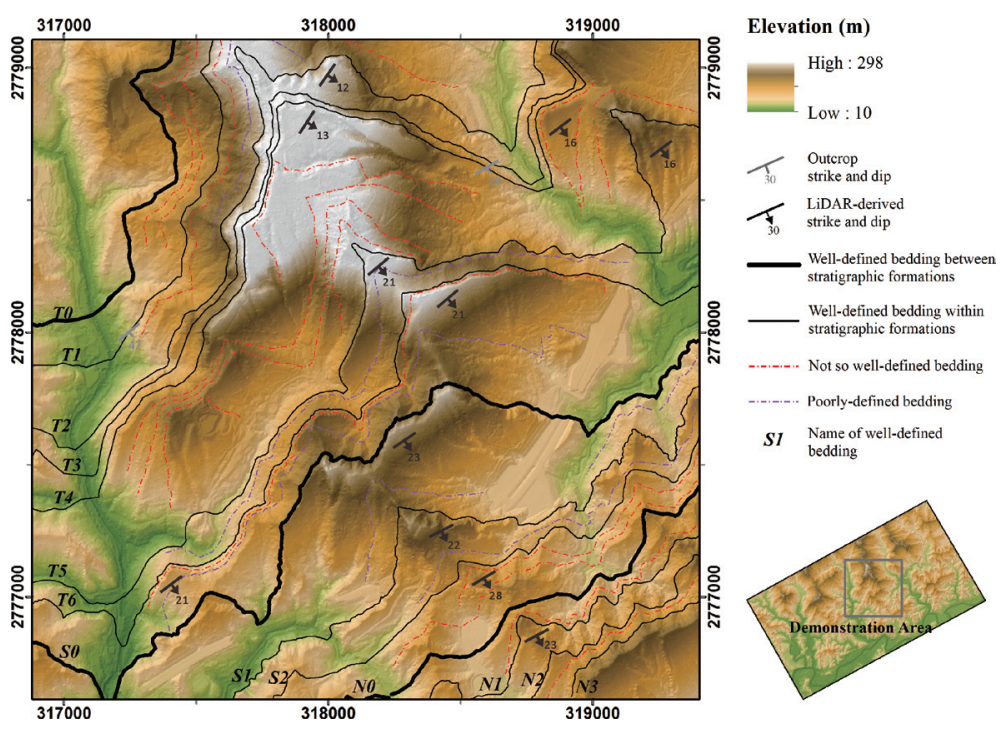

Fig. 14. A selected demonstration area showing the results of the improved geological mapping method proposed in this study for sedimentary terrain. The thick black lines represent well-defined beddings between stratigraphic formations (labeled as T0, S0, and N0). The thin black lines represent well-defined beddings within the stratigraphic formations. The purple dashed lines indicate not so well-defined beddings and the green dashed lines indicate beddings that are poorly defined.

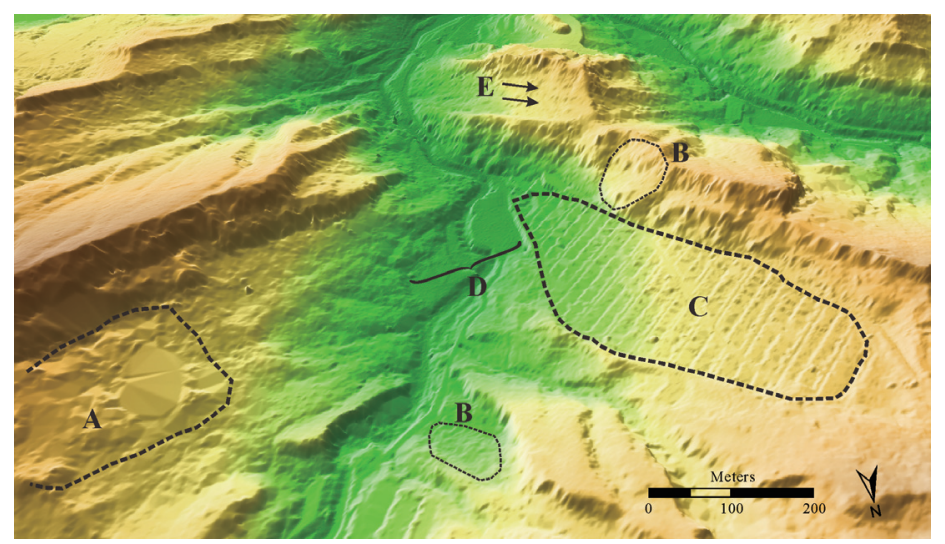

Fig. 15. Five situations affecting the mapping quality of strata boundaries using LiDAR data. A: Low density of LiDAR ground points. B: Debris deposition. C: Human constructions. D: River terraces. E: Little differential erosion. 
attitude and stratigraphic boundaries using an example in a monoclinal sedimentary terrain of northern Taiwan. In this $9.1 \times 5.1 \mathrm{~km}$ study area we demonstrated LiDAR-derived bedding strike and dip acquisition and interpolated smoothing bedding surfaces. The proposed approach provides more complete coverage and higher density bedding measurements, thereby supporting detailed geological mapping, in particular, for bedding trace and stratigraphic boundaries. We also effectively derived other significant geological information, including slightly curved 3D bedding surfaces and stratigraphic cross sections. This study demonstrates how to improve original geological maps with four major advantages of such improvements:

(1) Producing geological maps that are more representative and detailed than existing maps for engineering designs and geological disaster prevention.

(2) Establishing the methods and processing algorithms of remote sensing images, especially the LiDAR-derived 3D images for detailed and effective geological mapping.

(3) Providing quantified and digitized 3D bedding attitude and stratigraphic boundary for advanced geological and engineering numerical analysis.

(4) Introducing an efficient practice for detailed geological mapping in the laboratory to complement field observations.

Acknowledgments We thank the Central Geological Survey of Taiwan for sponsoring the airborne LiDAR survey in the research area. We also appreciate very much the useful and constructive reviews by Chyi-Tyi Lee, Ching-Weei Lin, and Editor Jian-Cheng Lee. The research was partly supported by the National Science Council of Taiwan with projects Nos. NSC102-2116-M-001-002 and MOST1032116-M-001-002. This is Institute of Earth Sciences, Academia Sinica contribution number IESAS 1901.

\section{REFERENCES}

Arrowsmith, J. R. and O. Zielke, 2009: Tectonic geomorphology of the San Andreas Fault zone from high resolution topography: An example from the Cholame segment. Geomorphology, 113, 70-81, doi: 10.1016/j. geomorph.2009.01.002. [Link]

Bedini,E., 2009: Mapping lithology of the Sarfartoq carbonatite complex, southern West Greenland, using HyMap imaging spectrometer data. Remote Sens. Environ., 113, 1208-1219, doi: 10.1016/j.rse.2009.02.007. [Link]

Bowman, D. A., E. Kruijff, J. J. LaViola Jr., and I. Poupyrev, 2004: 3D User Interfaces: Theory and Practice, Addison-Wesley Professional, $512 \mathrm{pp}$.

Bremer, M. and O. Sass, 2012: Combining airborne and terrestrial laser scanning for quantifying erosion and deposition by a debris flow event. Geomorphology, 138, 49-60, doi: 10.1016/j.geomorph.2011.08.024. [Link]
Carranza, E. J. M. and M. Hale, 2002: Mineral imaging with Landsat Thematic Mapper data for hydrothermal alteration mapping in heavily vegetated terrane. Int. J. Remote Sens., 23, 4827-4852, doi: 10.1080/01431160110115014. [Link]

Central Geological Survey (CGS), 2002: Lithological Unit Assemblage Map - Badu, Scale 1:25,000, Central Geological Survey, MOEA, Taiwan.

Central Geological Survey (CGS), 2005: Geologic Map of Taiwan - Taipei third ed., Scale 1:50,000, Sheet 4, Central Geological Survey, MOEA, Taiwan.

Chan, Y. C., Y. G. Chen, T. Y. Shih, and C. Huang, 2007: Characterizing the Hsincheng active fault in northern Taiwan using airborne LiDAR data: Detailed geomorphic features and their structural implications. J. Asian Earth Sci., 31, 303-316, doi: 10.1016/j. jseaes.2006.07.029. [Link]

Chang, K. J., A. Taboada, and Y. C. Chan, 2005: Geological and morphological study of the Jiufengershan landslide triggered by the Chi-Chi Taiwan earthquake. Geomorphology, 71, 293-309, doi: 10.1016/j. geomorph.2005.02.004. [Link]

Chang, K. J., Y. C. Chan, R. F. Chen, and Y. C. Hsieh, 2010: Evaluation of tectonic activities using LiDAR topographic data: The Nankan lineament in northern Taiwan. Terr. Atmos. Ocean Sci., 21, 463-476, doi: 10.3319/TAO.2009.11.17.01(TH). [Link]

Chen, R. F., K. J. Chang, J. Angelier, Y. C. Chan, B. Deffontaines, C. T. Lee, and M. L. Lin, 2006: Topographical changes revealed by high-resolution airborne LiDAR data: The 1999 Tsaoling landslide induced by the Chi-Chi earthquake. Eng. Geol., 88, 160-172, doi: 10.1016/j.enggeo.2006.09.008. [Link]

Crósta, A. P. and J. M. Moore, 1989: Geological mapping using Landsat Thematic Mapper imagery in Almeria Province, south-east Spain. Int. J. Remote Sens., 10, 505-514, doi: 10.1080/01431168908903888. [Link]

De Donatis, M., S. Susini, and M. Foi, 2012: Geology from real field to 3D modeling and Google Earth virtual environments: Methods and goals from the Apennines (Furlo Gorge, Italy). Geol. Soc. Am. Spec. Paper., 492, 221-233, doi: 10.1130/2012.2492(16). [Link]

De Rose, R. C. and L. R. Basher, 2011: Measurement of river bank and cliff erosion from sequential LIDAR and historical aerial photography. Geomorphology, 126, 132147, doi: 10.1016/j.geomorph.2010.10.037. [Link]

Dong, P. and B. Leblon, 2004: Rock unit discrimination on Landsat TM, SIR-C and Radarsat images using spectral and textural information. Int.J. Remote Sens., 25, 37453768, doi: 10.1080/01431160310001632675. [Link]

Drury, S. A., 1993: Image Interpretation in Geology, $2^{\text {nd }}$ edition, Chapman \& Hall, London, 336 pp.

Dueholm, K. S., A. A. Garde, and A. K. Pedersen, 1993: Preparation of accurate geological and structural maps, 
cross-sections or block diagrams from colour slides, using multi-model photogrammetry. J. Struct. Geol., 15, 933-937, doi: 10.1016/0191-8141(93)90186-E. [Link]

Glenn, N. F., D. R. Streutker, D. J. Chadwick, G. D. Thackray, and S. J. Dorsch, 2006: Analysis of LiDARderived topographic information for characterizing and differentiating landslide morphology and activity. Geomorphology, 73, 131-148, doi: 10.1016/j.geomorph.2005.07.006. [Link]

Grebby, S., D. Cunningham, J. Naden, and K. Tansey, 2010: Lithological mapping of the Troodos ophiolite, Cyprus, using airborne LiDAR topographic data. Remote Sens. Environ., 114, 713-724, doi: 10.1016/j. rse.2009.11.006. [Link]

Haugerud, R. A., D. J. Harding, S. Y. Johnson, J. L. Harless, C. S. Weaver, and B. L. Sherrod, 2003: High-resolution LiDAR topography of the Puget Lowland, Washington - A bonanza for earth science. GSA Today, 13, 4-10.

Howard, I. P., 2002: Seeing in Depth, Volume 1: Basic Mechanisms, University of Toronto Press, Canada, $659 \mathrm{pp}$.

Kooi, F. L. and A. Toet, 2004: Visual comfort of binocular and 3D displays. Displays, 25, 99-108, doi: 10.1016/j. displa.2004.07.004. [Link]

Kraus, K. and N. Pfeifer, 1998: Determination of terrain models in wooded areas with airborne laser scanner data. ISPRS J. Photogramm., 53, 193-203, doi: 10.1016/ S0924-2716(98)00009-4. [Link]

Kuenen, P. H., 1950: Stereoscopic projection for demonstration in geology, geomorphology, and other natural sciences. J. Geol., 58, 49-54, doi: 10.1086/625694. [Link]

Lan, H., C. D. Martin, C. Zhou, and C. H. Lim, 2010: Rockfall hazard analysis using LiDAR and spatial modeling. Geomorphology, 118, 213-223, doi: 10.1016/j. geomorph.2010.01.002. [Link]

Lato, M., J. Kemeny, R. M. Harrap, and G. Bevan, 2013: Rock bench: Establishing a common repository and standards for assessing rockmass characteristics using LiDAR and photogrammetry. Comput. Geosci., 50, 106-114, doi: 10.1016/j.cageo.2012.06.014. [Link]

Lee, C. T., K. H. Chiou, and Y. P. Chang, 2000: The technology and application of stereoscopic images. TiChih, 20, 49-64. (in Chinese)

Lisle, R. J., P. Brabham, and J. W. Barnes, 2011: Basic Geological Mapping, $5^{\text {th }}$ edition, John Wiley \& Sons, Chichester, $230 \mathrm{pp}$.

Rogge, D. M., B. Rivard, J. Harris, and J. Zhang, 2009: Application of hyperspectral data for remote predictive mapping, Baffin Island, Canada. Econ. Geol., 16, 209-222.

Roy, R., P. Launeau, V. Carrère, P. Pinet, G. Ceuleneer, H. Clénet, Y. Daydou, J. Girardeau, and I. Amri, 2009: Geological mapping strategy using visible near-infrared-shortwave infrared hyperspectral remote sens- ing: Application to the Oman ophiolite (Sumail Massif). Geochem. Geophys. Geosyst., 10, Q02004, doi: 10.1029/2008GC002154. [Link]

Seno, T., 1977: The instantaneous rotation vector of the Philippine sea plate relative to the Eurasian plate. Tectonophysics, 42, 209-226, doi: 10.1016/0040-1951(77)90168-8. [Link]

Suppe, J., 1980: A retrodeformable cross section of northern Taiwan. Proc. Geol. Soc. China, 23, 46-55.

Sutinen, R., E. Hyvönen, and I. Kukkonen, 2014: LiDAR detection of paleolandslides in the vicinity of the Suasselkä postglacial fault, Finnish Lapland. Int. J. Appl. Earth Obs., 27, 91-99, doi: 10.1016/j.jag.2013.05.004. [Link]

Taiwan Geotechnical Society (TGS), 2011: The investigation report of landslide at Taiwan highway No. 3, Ministry of Transportation and Communications Investigation Report, Taipei. (in Chinese)

Teng, L. S., 1990: Geotectonic evolution of late Cenozoic arc-continent collision in Taiwan. Tectonophysics, 183, 57-76, doi: 10.1016/0040-1951(90)90188-E. [Link]

Teng, L. S., C. T. Lee, C. H. Peng, W. F. Chen, and C. J. Chu, 2001: Origin and geological evolution of the Taipei basin, northern Taiwan. West. Pac. Earth Sci., 1, 115-142.

Twiss, R. J. and E. M. Moores, 2007: Structural Geology, $2^{\text {nd }}$ edition, W. H. Freeman, New York.

Van der Meer, F. D., H. M. A. van der Werff, F. J. A. van Ruitenbeek, C. A.Hecker, W.H.Bakker, M.F.Noomen, M. van der Meijde, E. J. M. Carranza, J. B. de Smeth, and T. Woldai, 2012: Multi- and hyperspectral geologic remote sensing: A review. Int. J. Appl. Earth Obs., 14, 112-128, doi: 10.1016/j.jag.2011.08.002. [Link]

Ventura, G.,G. Vilardo, C. Terranova, and E. B. Sessa, 2011 : Tracking and evolution of complex active landslides by multi-temporal airborne LiDAR data: The Montaguto landslide (Southern Italy). Remote Sens. Environ., 115, 3237-3248, doi: 10.1016/j.rse.2011.07.007. [Link]

Wang, L., J. H. Hwang, Z. Luo, C. H. Juang, and J. Xiao, 2013: Probabilistic back analysis of slope failure - A case study in Taiwan. Comput. Geotech., 51, 12-23, doi: 10.1016/j.compgeo.2013.01.008. [Link]

Webster, T. L., J. B. Murphy, J. C. Gosse, and I. Spooner, 2006: The application of LiDAR-derived digital elevation model analysis to geological mapping: An example from the Fundy Basin, Nova Scotia, Canada. Can. J. Rem. Sens., 32, 173-193, doi: 10.5589/m06-017. [Link]

Whitmeyer, S. J., J. Nicoletti, and D. G. de Paor, 2010: The digital revolution in geologic mapping. GSA Today, 20, 4-10, doi: 10.1130/GSATG70A.1. [Link]

Wickens, C. D. and J. G. Hollands, 1999: Engineering Psychology and Human Performance, $3^{\text {rd }}$ edition, Pearson, $573 \mathrm{pp}$. 